\title{
The Research on IMC-PID Control in Maglev Supporting System
}

\author{
Zheng Zhongqiao ${ }^{1,2, *}$, Wang Xiaojing ${ }^{1}$, Zhang Yanhong ${ }^{2}$, Xu Liang $^{2}$ and Chen Yanglin ${ }^{2}$ \\ ${ }^{I}$ School of Mechatronic Engineering and Automation, Shanghai University, Shanghai, 200072, China \\ ${ }^{2}$ School of Electronic Information \& Electric Engineering, Changzhou Institute of Technology, Changzhou, 213002, \\ China
}

\begin{abstract}
Highly efficient wind generator using magnetic suspension technology is discussed in this paper. The maglev wind generator can effectively reduce the mechanical resistance, and is characterized by longer life, higher efficiency, higher rotary speed and so on. By analysing the theory and usage of IMC-PID control used in maglev system of wind generator, mathematical model is built, and simuliation and analysis are made by MATLAB. The results show that IMCPID control is easily used becasuse parameters tunning only depends on the size of parameter $\alpha$, and is suited for maglev supporting system to use in wind generator, which provides some theoretical supports for follow-up research work.
\end{abstract}

Keywords: IMC-PID control, maglev supporting, MATLAB, simulation, wind generator.

\section{INTRODUCTION}

Power requirements for Chinese economic development and power production situations require active development of various renewable resources like wind power, hydro power and solar power which have good application prospects and popular value. Wind power is characterized by lower cost development, less impact on regional climate and has greater development potential. Developing the wind power generation using vast wind resources has profound strategic meaning for China [1].

In the past 20 years, installed wind energy capacity of China has grown quickly, and it is predicted that Chinese wind energy industry will continue its robust growth as the demand for energy has increased [2]. But because technical level of wind power equipment is lower at present, research and development level of key technologies have a big gap between China and foreign countries in high performance and large capacity wind turbines, and key equipments are still mainly imported. Manufacturing processes and technologies especially are lower than international standards in mechanical bearing, which becomes the "bottleneck" for wind power industry development, and is the key question to be resolved.

Along with the development and widespread use of high power devices, DSP and automatic control technology in recent years, magnetic suspension technology has made great strides and is used in electromagnetic bearing, maglev train, artificial heart pump and so on, especially in maglev processing platform, control precision has reached to nanoscale [3-5]. If mechanical bearing is replaced by electromagnetic bearing using magnetic suspension technology to otor system of wind generator, the "bottleneck" of wind power for the restriction of mechanical bearing can be solved, and the reactive situation can be broken that technologies and equipments are controlled by foreign countries.

\section{STRUCTURE OF WIND GENERATOR BASED ON MAGLEV SUPPORTING}

Vertical axis wind generator based on maglev supporting is mainly composed of auxiliary bearings, electromagnetic bearings, stator, rotor, permanent magnetic units, spindle, brushes \& slip rings and sensors, whose structure diagram is shown as Fig. (1).

Auxiliary bearing using roller or similar structure plays a role of spacing protection that include two aspects: supporting rotor system as braking or non-working status, and preventing rotor to touch electromagnetic bearing as the disturbance causes position shaking of rotor. Radial bearings use pairs of electromagnetic units to produce electromagnetic force on the rotor by differential model without any physical contact. Axial bearings using permanent magnetic units are main providers of magnetic field force in suspension to reduce supporting requirement of electromagnetic units. Displacement sensors detect the signal of rotor displacement, and transmit its values to controller.

\section{MATHEMATICAL MODEL OF MAGLEV SUP- PORTING SYSTEM}

Without consideration of electromagnetic coupling, total maglev supporting system can be devided into four independent single-degree-freedom control systems with same working principle. The model of single-degree-freedom maglev supporting system is shown as Fig. (2), in which, electromagnets work in difference way. In order to facilitate 


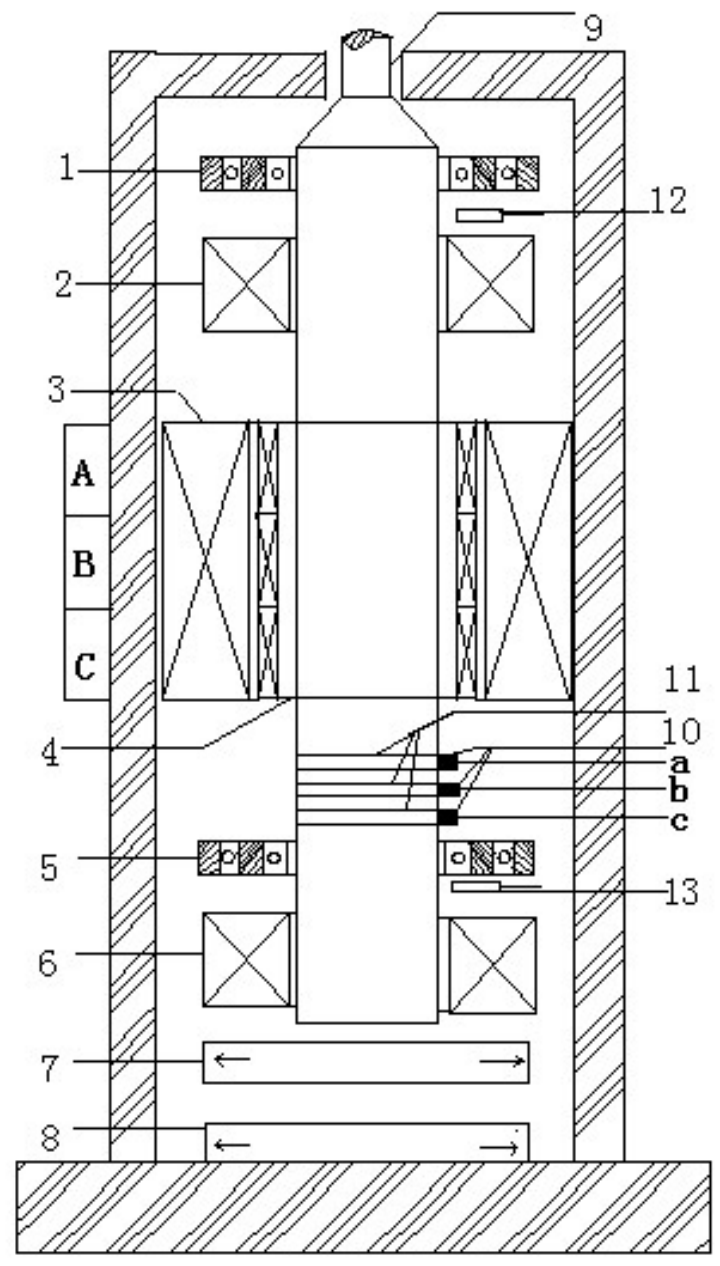

1,5- auxiliary bearings; 2,6- electromagnetic bearings;

3-stator; 4-rotor; 7,8- permanent magnetic units;

9-spindle; 10,11- brushes \& slip rings; 12,13-sensors

Fig. (1). Structure diagram of wind generator based on maglev supporting.

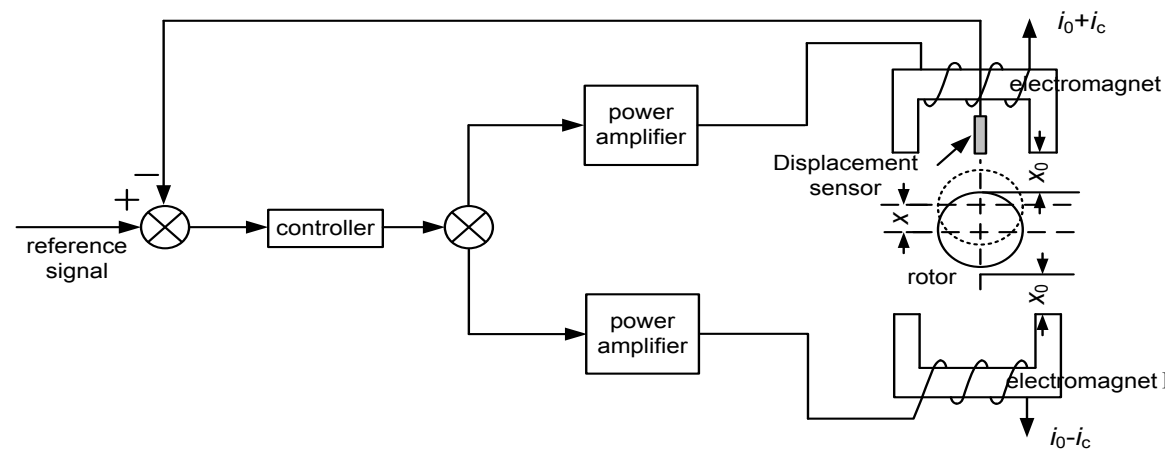

Fig. (2). Model diagram of single-degree-freedom maglev supporting system.

to analyzing the relationship between force on rotor, current and displacement, assumptions are made as following [6]:

(1) Regarding the rotor as single particle to processing;

(2) Neglecting leakage flux and edge-effects of the electromagnet, reluctance of core and rotor, hysteresis loss and eddy-current loss of magnetic material;
(3) Parameters of coils are same.

Based on Newton's second law, the mechanics relationship of single-degree-freedom motion is shown as following

$$
p(t)+F(i, x)=m \frac{\mathrm{d}^{2} x}{\mathrm{~d} t^{2}}
$$




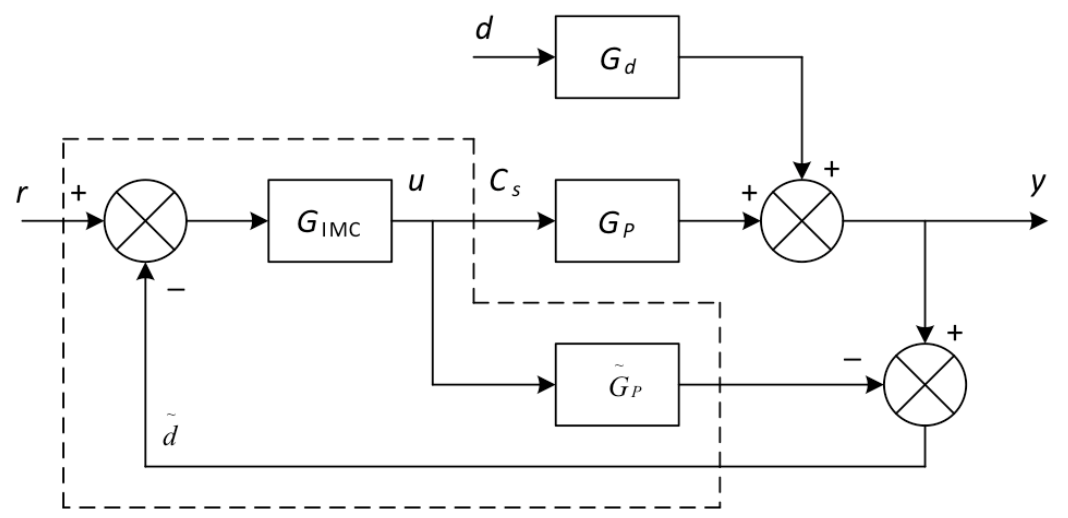

Fig. (3). Structure diagram of IMC system.

where $p(t)$ is external disturbance force that is a function of time; $F(i, x)$ is electromagnetism produced by magnetic bearing, which is a function of displacement and current; $m$ is the mass of rotor.

By a series of derivations based on Maxwell's equation and Ampere's circulation theorem, the expression of electromagnetic force can be obtained

$F(i, x)=k \frac{i^{2}}{x^{2}}$

where $k=\mu_{0} N^{2} A / 4$ in which $k$ is constant, $\mu_{0}$ is air permeability, $N$ is number of turns per coil, $A$ is total pole face area.

Putting equation (2) into (1), the following equation can be obtained

$m \frac{\mathrm{d}^{2} x}{\mathrm{~d} t^{2}}-k \frac{i^{2}}{x^{2}}=p(t)$

Obviously, the model of equation (3) is nonlinear secondary differential equation. In order to facilitate to analyzing and designing control system, equation (2) must be linearized. So, neglecting quadratic term and higher order term, the Taylor series expansion of the equation (2) can be obtained in very small neighborhood near the equilibrium point $\left(i_{0}, x_{0}\right)$ as follows:

$F(i, x) \approx F\left(i_{0}, x_{0}\right)+\frac{\partial F\left(i_{0}, x_{0}\right)}{\partial i}\left(i-i_{0}\right)+\frac{\partial F\left(i_{0}, x_{0}\right)}{\partial x}\left(x-x_{0}\right)$

By computing partial derivatives of equation (2), the following equations can be obtained at $\left(i_{0}, x_{0}\right)$ :

$\frac{\partial F\left(i_{0}, x_{0}\right)}{\partial x}=-\frac{\mu_{0} N^{2} A i_{0}^{2}}{2 x_{0}^{3}}=-k_{x}$

$\frac{\partial F\left(i_{0}, x_{0}\right)}{\partial i}=\frac{\mu_{0} N^{2} A i_{0}}{2 x_{0}^{2}}=k_{i}$

where $k_{x}, k_{i}$ are separately called displacement coefficient and current coefficient of magnetic bearing. When parameters of structure are certain, $k_{x}$ and $k_{i}$ are all constant. So

$F(i, x)=k \frac{i^{2}}{x^{2}} \approx F\left(i_{0}, x_{0}\right)+k_{i}\left(i-i_{0}\right)-k_{x}\left(x-x_{0}\right)$
Putting equation (7) into (3), the following equation can be obtained after sorting

$m \frac{\mathrm{d}^{2} x}{\mathrm{~d} t^{2}}-k_{i}\left(i-i_{0}\right)+k_{x}\left(x-x_{0}\right)-F\left(i_{0}, x_{0}\right)=p(t)$

where $F\left(i_{0}, x_{0}\right)$ is the electromagnetic force of magnetic bearing at static work point $\left(i_{0}, x_{0}\right)$, which is constant after parameters and static work point of magnetic bearing is determined. Setting $\Delta i=i-i_{0}=i, \Delta x=x-x_{0}=x$, then equation (8) can be simplified to the following

$m \frac{\mathrm{d}^{2} x}{\mathrm{~d} t^{2}}-k_{i} i+k_{x} x=p(t)$

Using Laplace transformation for (9), the following equation can be obtained

$m s^{2} X(s)-k_{i} I(s)+k_{x} X(s)=P(s)$

where $X(s), I(s)$ and $P(s)$ respectively are the Laplace transformation of displacement function $x(t)$, current function $i(t)$ and external disturbance force function $p(t)$.

\section{IMC-PID CONTROL SYSTEM}

IMC(internal model control) is a kind of new control tactic designed based on the mathematical model of the process [7], which didn't need a lot for accurate model of controlled object, and is used to first-order or second-order time delay system, whose control only needs one parameter to be set, so it is easy to achieve. Fig. (3) is the structure diagram of IMC, where $G_{\mathrm{IMC}}$ is IMC controller, $G_{\mathrm{P}}$ is transfer function of controlled object, $G_{P}$ is the model of the object, $G_{\mathrm{d}}$ is the influence of disturbance on the output.

Design step of IMC controller is as the following [8]:

(1) Determining internal model $\tilde{G}_{P}(s)$;

(2) Decomposing internal model $\tilde{G}_{P}(s)$ into two parts $\tilde{G}_{P+}(s)$ and $\tilde{G}_{P-}(s)$, that

$\tilde{G}_{P}(s)=\tilde{G}_{P+}(s) \tilde{G}_{P-}(s)$ 


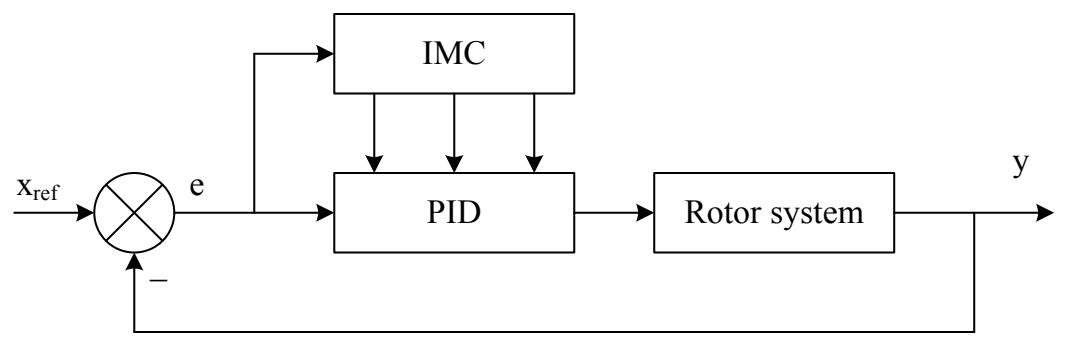

Fig. (4). Structure diagram of system simulation.

Table 1. Traditional PID control scheme.

\begin{tabular}{|c|c|c|c|}
\hline Control scheme & $\boldsymbol{k}_{\mathrm{p}}$ & $\boldsymbol{k}_{\mathbf{i}}$ & $\boldsymbol{k}_{\mathrm{d}}$ \\
\hline \hline first control & 4 & 800 & 0.03 \\
\hline second control & 10 & 800 & 0.03 \\
\hline third control & 10 & 500 & 0.03 \\
\hline fourth control & 50 & 800 & 0.03 \\
\hline
\end{tabular}

Where $\tilde{G}_{P-}(s)$ is the transfer function with minimum phase characteristics which is stable and without predictive term, $\tilde{G}_{P+}(s)$ includes all time delays and zero points in the right-half plane.

(3) Defining IMC controller as the following

$$
G_{I M C}(s)=\tilde{G}_{P}^{-1}(s) \bullet \frac{1}{\left(T_{f} s+1\right)^{n}}
$$

where order $n$ depends on the order of $\tilde{G}_{P_{-}}(s)$ to ensure that $G_{\text {IMC }}(s)$ can be achieved, $T_{f}$ is the coefficient of filter.

\section{APPLICATON OF IMC CONTOLLER IN MAGLEV SUPPORTING SYSTEM}

Choosing appropriate transfer function, setting $G_{P}(s)=\tilde{G}_{P}(s)$, without consideration for interference, closeloop transfer function is as the following

$\frac{Y(s)}{R(s)}=G_{I M C}(s) G_{P}(s)$

Setting

$G_{I M C}(s)=\frac{1}{(1+\alpha s)^{n}} \tilde{G}_{P}^{-1}(s)$

then equation (14) is changed to

$$
G(s)=\frac{Y(s)}{R(s)}=\frac{1}{(1+\alpha s)^{n}}
$$

at the same time the following equation can be obtained
$C_{s}(s)=\frac{G_{I M C}}{1-G_{I M C} \tilde{G}_{p}(s)}$

The transfer function of magnetic bearing is as following

$G_{p}(s)=\frac{k_{y}}{m s^{2}-k_{x}}$

It can be seen from equation (17) that the maglev system is of opening loop instability, so correction link need be added to the system to eliminate the pole in right-half plane, then the system is changed to stable one-order inertial link.

Taking $\mathrm{n}=1$, then

$C_{s}(s)=\frac{1}{\alpha s} \tilde{G}_{P}^{-1}(s)$

$\tilde{G}_{P}(s)$ is one-order inertial link, then $C_{\mathrm{s}}(s)$ finally changes to common PI controller. The structure diagram of system is as Fig. (4).

\section{SIMULATION AND ANALYSIS BY MATLAB}

The system simulations adopting IMC PID and traditional PID control principle respectively are made with MATLAB/SIMULINK software, where the position of zero point is of the rotor supported by auxiliary bearings without maglev supporting, and stable position is the center position at which the rotor is as stable levitation. The simulation results are as Fig. (5) and Fig. (6).

It can be seen from Fig. (5). that the unit step response of system presents some regularity as following. As $\alpha=20$, system response has a overshoot of 5 precent; As $\alpha=15$, the overshoot has dropped to very small and the system is tending towards stability at $t=0.02 \mathrm{~s}$; As $\alpha=5$, though the system has not a overshoot, response rate is so slow that the system is not tending towards stability until $t=0.06 \mathrm{~s}$. 


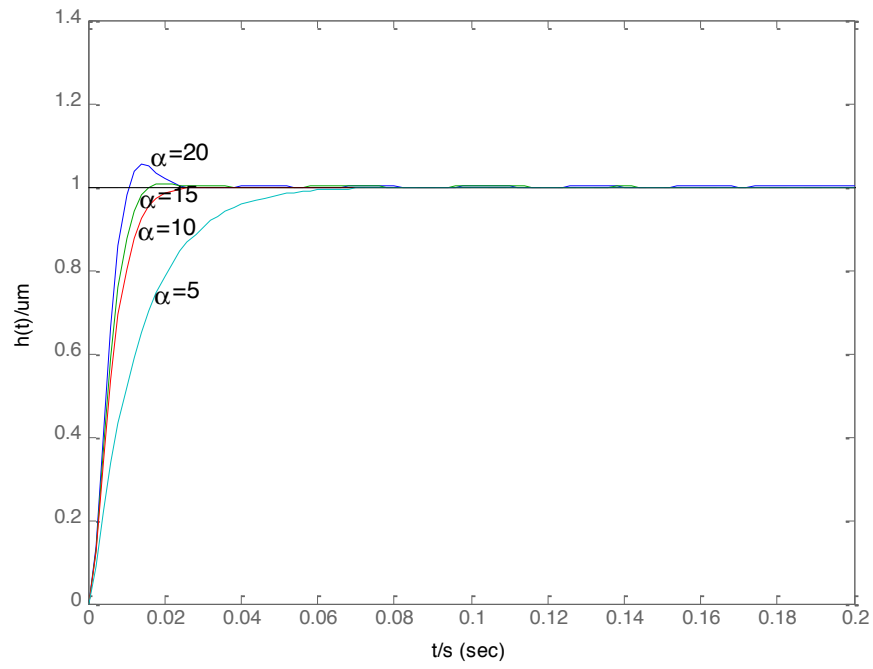

Fig. (5). The unit step response curves of IMC.

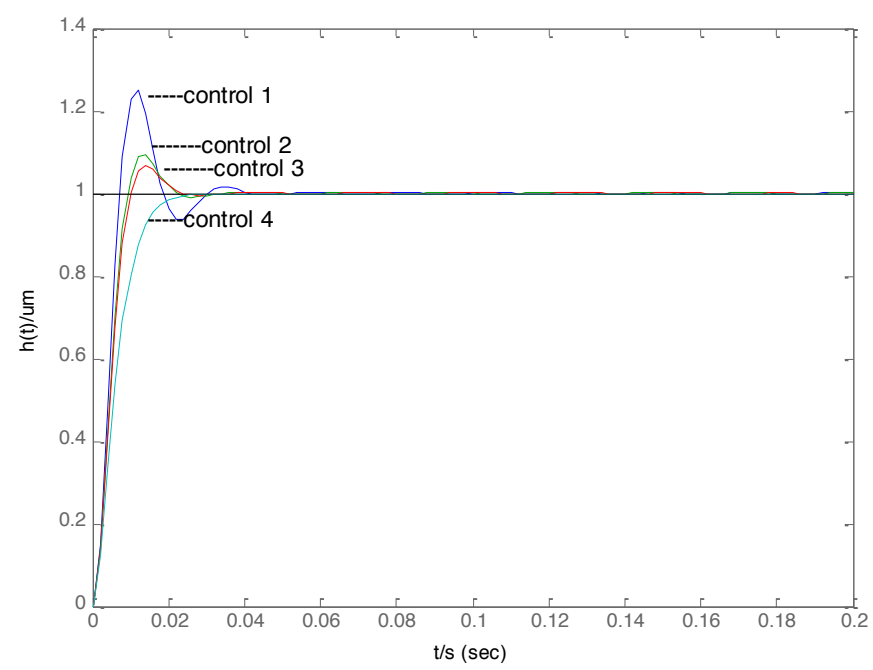

Fig. (6). The unit step response curves of traditional PID control.

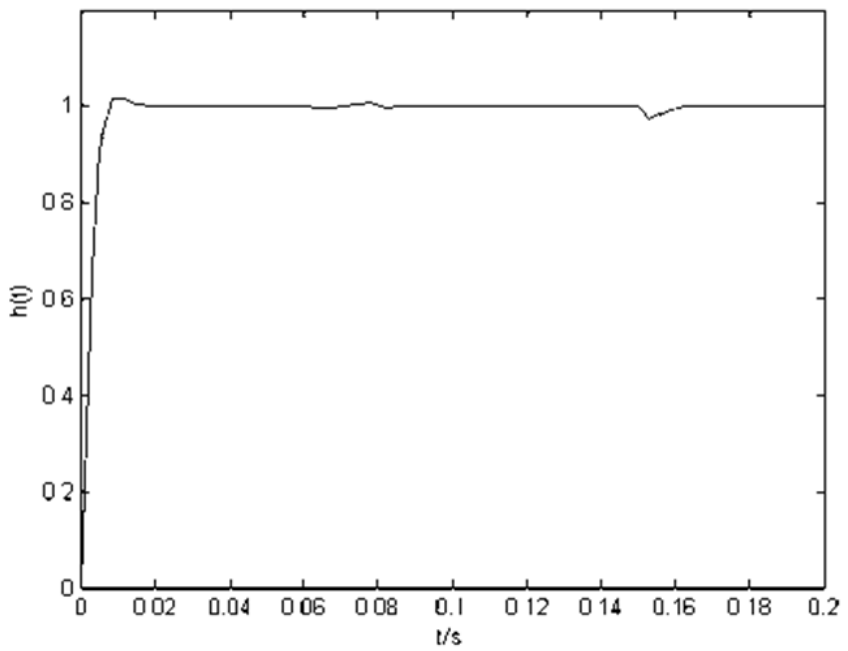

Fig. (7). The disturbance response curve under IMC. 




Fig. (8). The disturbance response curve under traditional PID control.

Table 1 has given control state of traditional PID. It can be seen from Fig. (6). that traditional PID control whose parameters is difficult to tunning, is not easy to find appropriate parameters, does not achieve the expectation effect, still does not eliminate the overshoot and improve the stable time even in the case of the fourth control.

In order to verifying the response of external disturbance, a disturbance whose magnitude is $0.01 \mathrm{~cm}$ is added to the system. The unit step response curves of the system can be observed at disturbed state as Fig. (7), Fig. (8). With the action of IMC, the system can recover stability after $0.02 \mathrm{~s}$, but the system adopting traditional PID control need $0.1 \mathrm{~s}$ to recover stability. Obviously, the system with the action of IMC has stronger anti-jamming capacity and faster recovery speed.

\section{CONCLUSION}

By analyzing the development of wind generator, this paper pointed out the problem existing in wind generator, brought forward the scheme applying magnetic bearing to wind generator, analyzed the composition of wind generator based on maglev supporting, and built the mathematical models of maglev supporting system. Then this paper proposed applying IMC PID control system to maglev supporting system of wind generator, and simuliation and analysis are made by MATLAB. The results show that IMC-PID control is easily used becasuse parameters tunning only depends on the size of parameter $\alpha$, and is suited for maglev supporting system to use in wind generator, which provides some theoretical support for follow-up research work.

\section{CONFLICT OF INTEREST}

The authors confirm that this article content has no conflict of interest.

\section{ACKNOWLEDGEMENTS}

We acknowledge the help of Jiansheng Zhang, Bing Zhang and Wensheng Huang in research. We also thank the anonymous reviewers for their numerous helpful suggestions. The work was supported by the National Nature Science Foundation of China (No. 51175052) and Applied Basic Research Programs of Changzhou City (No. CJ20130014), also supported by Scientific Research Fund of Changzhou Institute of Technology (No.YN1216), respectively.

\section{REFERENCES}

[1] X. Daping, L. Yibing, L. Yuegang, Eds., Principle of Wind Power. China Machine Press: Beijing, 2011.

[2] N. S. Bao, X. Q. Ma, W. D. Ni, "Investigation on the integral output power model of a large-scale wind farm," Frontiers of Energy and Power Engineering in China, vol. 1, no. 1, pp. 67-78, January 2007.

[3] K. -H. Becker, "Magnetic bearings for smart aero engines," In: Proceedings of $13^{\text {th }}$ International Symposium on Transport Phenomena and Dynamics of Rotating Machinery, pp. 417-422, April 2010

[4] F. W. Werfeil, U. Floegel-Delor, "Flywheel energy storage system with magnetic bearings," In: Proceedings of $8^{\text {th }}$ International Symposion on Magnetic Suspension Technology, pp. 256-260, September 2005.

[5] J. Jugo, I. Lizarraga, I. Arredondo, "Nonlinear modelling and analysis of active magnetic bearing systems in the harmonic domain: a case study," IET Control Theory and Applications, vol. 2, no. 1, pp. 61-71, 2006.

[6] W. Xiping, Parameters Design and Applied Research of an Active Magnetic Bearing System, Xi'an Jiaotong University: Xi'an, 1994.

[7] H. Shuju, Z. Dongli, G. Jindong, "Study on the internal model control tactic of PMSG for direct-driven wind power system," Renewable Energy Resources, vol.27, no. 3, pp. 21-26, June 2009.

[8] C. Jing, Q. Haichen, "Application of IMC PID in temperature control system of rfid packing equipment," Machine Building \& Automation, vol. 21, no. 4, pp. 206-208, June 2012.

Received: November 26, 2014

(C) Zhongqiao et al.; Licensee Bentham Open.

This is an open access article licensed under the terms of the Creative Commons Attribution Non-Commercial License (http://creativecommons.org/licenses/by-nc/3.0/) which permits unrestricted, non-commercial use, distribution and reproduction in any medium, provided the work is properly cited. 